\title{
Research on Beyond Meat's Profitability Problems and Strategies
}

\author{
Man Chen ${ }^{1, *}, \dagger$ Yingyue Wang ${ }^{2, \dagger}$ \\ ${ }^{1}$ Guangzhou Foreign Language School, Guangzhou 511466 China \\ ${ }^{2}$ School of Finance, Nankai University, Tianjin 300350 China \\ ${ }^{*}$ Corresponding author. Email: ${ }^{b}$ yingyue@mail.nankai.edu.cn \\ ${ }^{+}$These authors contributed equally.
}

\begin{abstract}
With the rapid growth of the global population, there must be suggestions on the world's food security. Artificial meat may become a potential substitute for conventional meat. Despite the increasing demand in the worldwide range and the mass injection of venture capital, the industry faces a shortage of profit, sometimes even a loss. Therefore, an investigation of what causes the failure of profitability in this newly-born industry should be done. This article mainly contains the following four methods: literature analysis, case study, induction and generalization, and the method of comparison. This paper focuses on Beyond Meat, one of the dominant companies in the alternative meat industry as a typical case. It is concluded that the inadequacy of operating revenue and the redundancy of expense are two primary defects of the enterprise, as the firm's profile has been drawn and six key indexes of profitability computed. To solve the problems in the future, the management layer is supposed to improve the advertisement plan, cut down its processing and selling costs, guarantee a certain level of cash flow, focus on product research and development and strengthen the nexus with strategic partners. A combination of the strategies mentioned above can be used as a tentative reference for future business and operating proposals in the artificial meat industry at company's level.
\end{abstract}

Keywords: Artificial Meat, Beyond Meat, Profitability, Problem, Strategy.

\section{INTRODUCTION}

As the overall population constantly follows an increasing trend, it is reasonable that there will be implications with world sustainable food production in the future. According to the Food and Agriculture Organization (FAO), by 2050, 70\% more food will be produced to meet the demand for the growing population. To accommodate the increasing demand for food, scientists are seeking to find alternative materials and developing new sustainable food technology. As one of the potential solutions, artificial meat starts to occur recently as a substitute for conventional meat. Artificial meat is either cultured meat or plant-based meat. Cultured meat is meat produced by in vitro cell culture of animal cells instead of from slaughtered animals [1]. Another on-the-horizon alternative to conventional meat is plant-based meat imitation meat products such as textured vegetable protein [2]. From previous study, artificial meat production involves lower use of energy, emission, amount of water, and land use. What's more, the whole production cycle is shortened
[3]. In addition to providing enough food for future population, novel food is developed for environmental cause. Food made artificially ensures that the possibility of being contaminated or carrying flu is significantly reduced. Thus, clean meat is likely to attract a considerable number of potential customers.

Seeing the potential in the global market, a company Beyond Meat was founded in 2009. As one of the artificial companies that produce plant-based meat. Since 2013, Beyond Meat receives venture funding from numerous investors, including Bill Gates and Tyson Foods. Until 2018, Beyond Meat had received $\$ 72$ million in funding [4]. However, the firm's sales face a deficit. Indeed, the artificial meat industry has the potential of gaining profits. A further study investigating the deficit in sales needs to be done.

Researchers have investigated the main challenges in commercializing plant-based meat alternatives. It turns out that with the development and progress the whole artificial meat industry have made, plant-based meat alternative will face competition with other meat 
alternatives like lab-grown meat industry [5]. Thus, the continuous loss incurred by the firms in the plant-based meat industry is partially due to the heating up of competition among firms and different industries over time. A corporation with catering restaurants and retail stores are critical in improving the firms' sales [6]. Furthermore, the cost of producing plant-based meat alternatives is high. Because the process involves adding a great variety of nutritional ingredients and additives to ensure the taste is similar enough to conventional meat and the nutritional value is attained [7]. This is one of the challenges among plant-based meat companies mentioned in previous researches. Certain studies also mentioned the geographical factor as a spread of the artificial meat companies over different geographical regions as uncertainty that influences the sales [8]. As the firms settle in different regions, in which people's incomes are unequal, the sales can be different from different retail stores.

Also, many reports highlight the COVID-19 pandemic as the cause for this food service challenge [9]. Previous investigations showed that the pandemic dramatically reduces the sales and profits for the whole food service industry. As Beyond Meat gradually accommodates the effect COVID-19 brings and navigated the transition of sales from restaurants to grocery chains led by pandemic force along 2020, the company ought to receive better deals. Meanwhile, the latest quarterly earnings data has yet to show an accordingly better situation. Despite the few study testifying factors relating to the sales, the factors aren't specific enough. Instead, previous studies only provided an overview of the elements involved. What's more, few studies had done using particular data to explain sales deficit for firms in plant-based meat alternative industries like Beyond Meat. As a result, the cause for directly related Beyond Meat's recent sales isn't specified clearly. Firms enduring the same sales deficit as Beyond Meat had yet to find the solutions and take action.

This study aims to summarize the company Beyond Meat's performance in the market and explain the cause of incurring loss recently. Then, this article will provide solutions and advice based on the analysis related to the cause of the deficit. The article involves in the literature review to provide insight into the clean meat industry and its financial situation. The case analysis is done based on the company Beyond Meat. Then, this research will use induction and generalization to conclude the result. Also, this study includes a comparison-conduct vertical comparison for the company's results data and conduct parallel comparison for Beyond Meat with other companies. By this mean, can this study derive the conclusion and analysis.

\section{METHODOLOGY}

\subsection{Literature Analysis}

Literature analysis means exploring in the previous texts on the topic of the research, interpreting its meanings, and analyzing them in a generalized way [10]. In this article, there is a special part lying in the introduction part for using the literature analysis method in which the development of the relevant historical research is sorted out. The researchers have mentioned the challenges of competing goods, high production costs, regional influences and the effect of COVID-19 previously. An overall literature analysis will better understand the existing problems in lifting up the sale of alternative meat and find out the corresponding solution by focusing on the blind spots in recent research.

\subsection{Case Study}

Gerring and John characterize the case study approach as a "seriously consider of a single unit or a little number of units (the cases), for the reason of understanding a bigger lesson of comparative units (a populace of cases)". According to his textbook, the key characteristic of case study from all other methods is the "dependence on prove drawn from a single case and its endeavors, at the same time, to light highlights of a broader set of cases [11]."

It can be considered that case analysis is the primary method used in this study. This study chose Beyond Meat, a newly-launched company in NASDAQ, as a representative sample to make a thorough inquiry in the market strategy for the companies in the artificial meat industry. After a brief profile of the enterprise, six common profitability indexes were calculated by its financial statements ranked in a chronological sequence and presented in the form of tables and figures. Then the influencing factors were extracted and discussed and corresponding solutions were found at the same time. Finally, a tentative optimum proposal was also provided.

\subsection{Induction and Generalization}

Defining the term of induction starts by analyzing a small number of cases of the phenomenon to be investigated, searching for similarities that may point to common factors [12]. Once the similarities have been found, a conclusion is generalized on them. The method of induction and generalization is mainly utilized at the end of a part to give a phased or an overall result. To be specific, in the third section of the main body, facts and data about the Beyond Meat case are given and it also did some preliminary calculation and induction work, such as extracting what commonly led to negative indexes and the loss of the whole corporation. The next discussion part is an advanced investigation. Each influencing factor of profitability can find a 
corresponding strategy in the latter induction and the final conclusion includes a combination of these main findings.

\subsection{Comparative Method}

Comparison, to some extent, is a supplemental method to the case study method in this article. A typical comparable company analysis involves comparing operating metrics and valuation multiples for public companies in a group of peer companies that are similar to target company in terms of size, business and other criteria [13]. Due to the limitation of length and topic, only qualitative comparations about operating stratagem among Impossible Food, Tyson Food and Beyond Meat are mentioned in the discussion part.

\section{RESULT}

\subsection{Brief State of the Artificial Meat Industry}

Unlike other industries, the traditional meat industry cannot scale up production to satisfy the expanding market demand, so a replacement of animal protein is or will be necessary. As an environmental-friendly substitution of meat, poultry, eggs and seafood, alternative proteins, also better-known as artificial meat, is aiming at more than $97 \%$ meat-eaters, according to Amy Huang. She is a university innovation manager at nonprofit think tank Good Food Institute [14]. Regardless of the heat in stock investment, there exists few bubbles in this industry. It is because this new-born field is only ten years old or so, and some of the relevant technology still has to be advanced. For example, cellcultured protein products still have whitespace in industrial mass production [15].

Nowadays, the investment track of artificial meat is deeply favored by hot money (see Figure 1 below) [14]. On the one hand, newly-listed or will-be-listed companies like Beyond Meat, Impossible Foods and Eat Just are eager for capital injection and expansion. On the other hand, traditional food giants like Nestle and Unilever are preparing to open their own synthetic proteins' production line. However, the upsurge of artificial protein closely related to the hot holding of capital is in sharp contrast to the net loss in its sale. The synthetic meat industry still remains a long way to go.

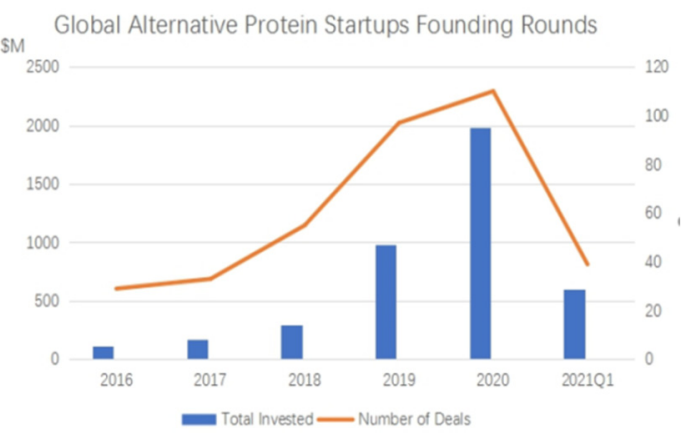

Figure 1 Global alternative protein startups founding rounds (up till April 23, 2021).

\subsection{Beyond Meat's Current Situation}

\subsubsection{Profile}

Beyond Meat Inc. was incorporated in Delaware on April 8, 2011, and is one of the speediest developing food companies in the United States, offering a revolutionary plant-based Meat portfolio. It produces meat specifically from plants by using an innovation that enables consumers to experience the taste, texture and other sensory properties of prevalent animal-based meat products, while enjoying the nutritional value of eating plant-based meat. Their brand commitment "Eat What You Love" represents a firm belief that consumers can appreciate more of their favorite foods. In addition, the company also highlights issues related to human health, climate change, resource conservation and animal's wellbeing. In 2019, Beyond Meat debuted on the New York Stock Exchange, jumping $163 \%$ on its first day of trading and has become the biggest one-day IPO gain since the 2008 financial crisis, which has been famous for the "first stock of artificial Meat."

\subsubsection{Profitability Index}

\subsubsection{Operating Profit Ratio}

Operating profit ratio: According to the table I and Fig. 2, the operating profit ratio (OPR), which is a direct index of a company's operating ability of main business, increased sharply from 2016 to 2019 and then illustrated a general decrease in the next two years. However, the ratio has been negative since the operating profit is always under zero.

Table 1. Operating profit ratio (2016-2021Q1)

\begin{tabular}{ll}
\hline Time & Operating profit ratio (OPR) \\
\hline 2016 & $-155.39 \%$ \\
2017 & $-90.75 \%$ \\
2018 & $-33.11 \%$ \\
2019 & $-1.20 \%$ \\
2020 & $-12.76 \%$ \\
2021 & $-23.37 \%$ \\
\hline
\end{tabular}




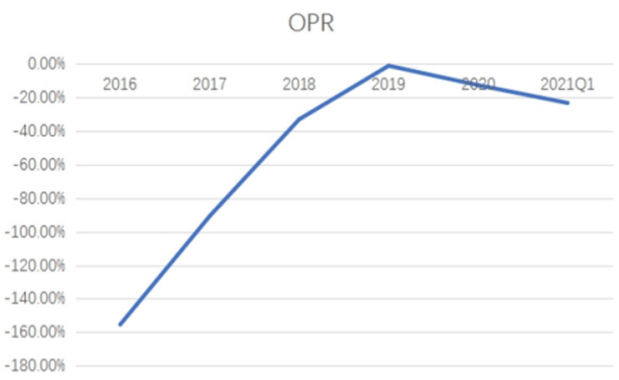

Figure 2. Operating profit ratio (2016-2021Q1).

\subsubsection{Ratio of Profits to Cost and Expense}

From Table 2 and Figure 3, it can be seen that Ratio of Profits to Cost and Expense (RPCE) shows how much profit can be gained by paying one dollar's cost expense, reflecting the operating results brought by operating expenses. It has had a similar trend to that of OPR and it is the minus value of net income that contributes to the consistent negative RPCE.

Table 2. Ratio of profits to cost and expense (20162021Q1)

\begin{tabular}{ll}
\hline Time & $\begin{array}{l}\text { Ratio of profits to cost and } \\
\text { expense }\end{array}$ \\
\hline 2016 & $-130.89 \%$ \\
2017 & $-107.07 \%$ \\
2018 & $-62.50 \%$ \\
2019 & $-11.70 \%$ \\
2020 & $-29.84 \%$ \\
2021 & $-46.52 \%$ \\
\hline
\end{tabular}

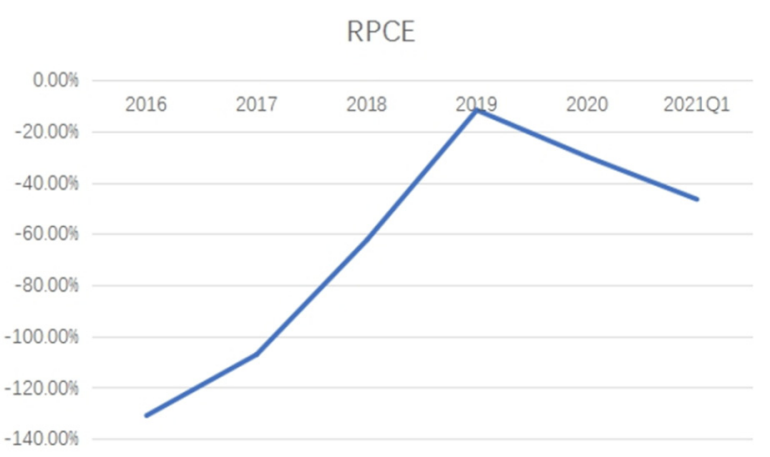

Figure 3. Ratio of profits to cost and expense (20162021Q1).

\subsubsection{Earnings/Cash Ratio}

As shown in Table 3 and Figure 4, in condition of accounting on the cash basis, the ratio of earnings to cash $(\mathrm{E} / \mathrm{C}$, and also known as security surplus cash multiple, SSCM) reflects how much of the current net income of the enterprise is under the protection of cash. The $\mathrm{E} / \mathrm{C}$ value of Beyond Meat has been approximate to or above one during the period from 2016 to 2021 Q1, which indicates an appropriate protection of cash flow.

Table 3. Earnings/cash ratio (2016-2021Q1)

\begin{tabular}{ll}
\hline Time & Earnings/cash ratio $(\mathrm{E} / \mathrm{C})$ \\
\hline 2016 & 0.934232 \\
2017 & 0.831786 \\
2018 & 1.262163 \\
2019 & 3.776822 \\
2020 & 0.75817 \\
2021 & 1.124367 \\
\hline
\end{tabular}

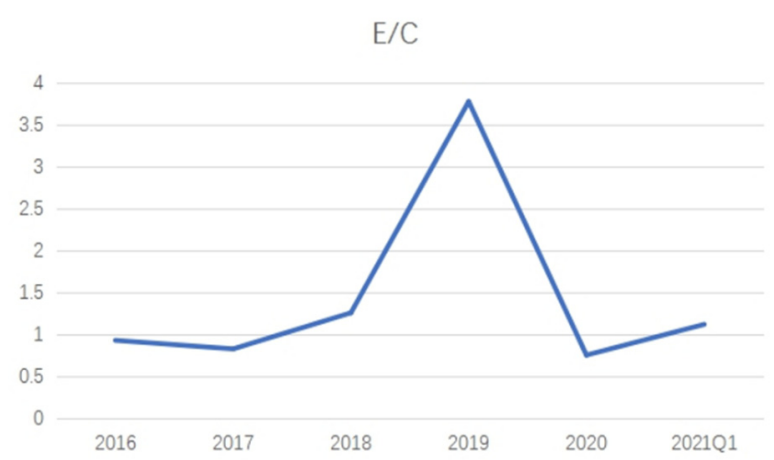

Figure 4. Earnings/cash ratio (2016-2021Q1).

\subsubsection{Return on Total Assets Ratio, Equity and Capital}

As shown clearly in Table 4 and Figure 5, In order to evaluate the overall profitability of the enterprise using all sorts of assets, return on total assets ratio spans across balance sheet and profit statement and has a quality of time interval of the company. To sum it up, it has been increasing since four years ago. As one of the most common investment reference indicators, return on equity (ROE) is an important financial index to measure the efficiency of shareholders' funds. It demonstrates a similar trend to return on total assets ratio (RTAT), although the value of ROE is always below RTAT in the sample period. Meanwhile, the index of return on capital (ROC) is an indicator of the ratio of debt and equity. The higher the rate of ROC is, the better the economic benefit of the enterprise's own investment (equity), the less the risk for investors, and it is worth continuing to invest. Since the ROC of Beyond Meat is below zero, it can be concluded that leverage is supposed to be added in the future financial stratagem. 


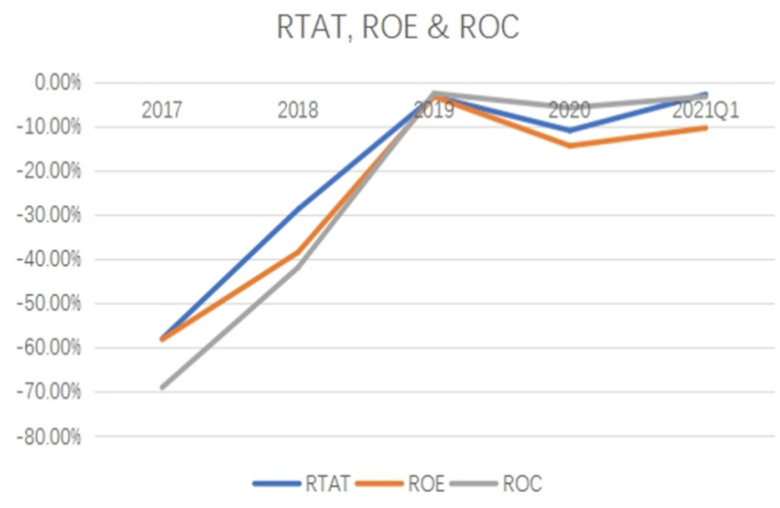

Figure 5. RTAT, ROE and ROC (2017-2021Q1)

Table 4. RTAT, ROE and ROC (2017-2021Q1)

\begin{tabular}{llll}
\hline Time & RTAT & ROE & ROC \\
\hline 2017 & $-57.94 \%$ & $-58.12 \%$ & $-68.97 \%$ \\
2018 & $-28.73 \%$ & $-38.42 \%$ & $-41.85 \%$ \\
2019 & $-3.20 \%$ & $-3.24 \%$ & $-2.50 \%$ \\
2020 & $-10.89 \%$ & $-14.37 \%$ & $-5.74 \%$ \\
2021 & $-2.74 \%$ & $-10.33 \%$ & $-3.25 \%$ \\
\hline
\end{tabular}

\subsection{Factors Affecting Profitability}

Overall, it can be inferred from the profitability indexes' calculation process that it is the negative profit, both the operating and the net one, that result in a minus outcome. In terms of the accounting equation, it can be considered from the revenue and expense sides.

\subsubsection{Operating Revenue}

Though the operating revenue of Beyond Meat in 2020 has been more than 25 times as much as that in 2016 , still it could not cover the expenses. Luckily the gross profit turned from loss to positive in 2018 and has since been maintaining a proportional growth to operating revenue. Despite the black swan event COVID-19, Beyond Meat considers exploring new markets as an important strategy, offering a space to lift its sale.

\subsubsection{Cost and Expenses}

At present, expenses are out of proportion to revenues. It is the core factor that contributes to the low level of profitability. It is worth mentioning that Beyond Meat's interest expense is small, which is not shown in Figure 6 and it is because of its low-leveraged asset structure. Besides, operating cost and selling and administrative expense takes most of the income part.

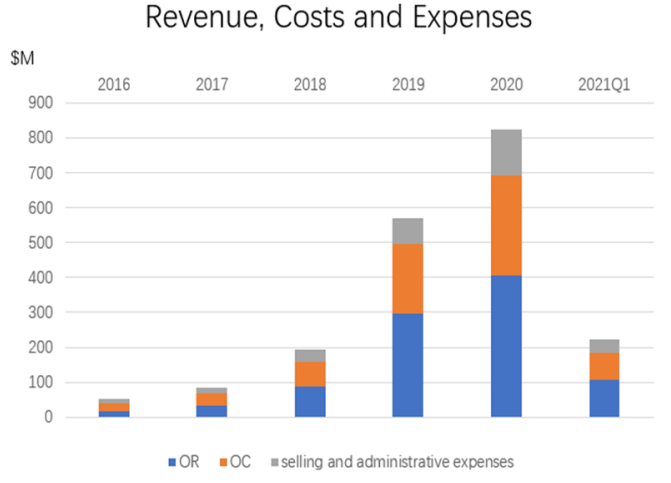

Figure 6. Revenue, costs and expenses (2016-2021Q1).

\section{DISCUSSION}

\subsection{Explore New Market}

Beyond Meat's operating profit ratio has witnessed a decrease starting from 2019 being negative since its operation. The operating profit ratio is the ratio of operating profit and net sales. When focusing on operating profit, the non-operating income decreases significantly from positive at the last quarter of 2019 to the last quarter of 2020, mainly due to a decrease in product sales.

Considering the impact that COVID-19 brings to the whole foodservice industry, it's reasonable to predict a sharp decrease in sales as an effect. After struggling with the deficit in profits since the pandemic, Beyond 
Meat should pay more attention to online sales. As the pandemic might further affect food service industry and this company, it's worth exploring the online market and sells the products directly through websites or digital applications.

A well-operated firm ought to have great popularity among the public. Thus, Beyond Meat is still on its way to raise public awareness with its novel products. In order to open up new markets and promote the products to the masses, Beyond Meat should improve its advertisement level by developing new marketing strategies. In addition to a vegetarian diet or being environmental-friendly, the firm can highlight the health and taste their plant-based meat products can bring about.

\subsection{Adjust Operating Costs}

In order to lower the ratio of profits to cost and expense to approach a positive value, the firm should reduce the cost. Until now, the costs and expenses are out of proportion to revenues and it has become severer since 2019. On the one hand, one of the most proper actions is to reduce operating costs based on the current situation. Beyond Meat can adjust its costs either in processing or selling, such as marketing costs, operating costs and management costs. With the development of the online market as mentioned to increase the operating profit ratio, selling can be greatly reduced depending on these automatic online systems. On the other hand, the concept of designing new products for customers can't be ignored. Thus, the expense of developing novel food would rather increase so that the products can continuously serve worldwide customers' satisfaction and thus create higher returns.

\subsection{Invest and Cooperate}

The cash ratio of Beyond Meat fell below one since 2020 , indicating a negative net margin was incurred. The firm holds few cash among its revenue, which also limits its ability to pay back for loans when incurring a deficit. As a result, the firm should improve cash flow and increase the security surplus cash multiple. The way companies facilitate their funds actually plays a role in their developing prospect. As a case here, Beyond Meat can focus on storing recovered funds. Also, like other plant-based meat alternatives firms, Beyond Meat can invest in firms or financing projects to collect available cash. As a competitor in the artificial meat industry, Tyson Food focuses on newer listed companies and invests in Beyond Meat with venture funds. Choosing a listed company with great potential to invest is a plausible way of increasing cash flow, especially longterm. In turn, Beyond Meat can also issue new shares to pay off debts. Moreover, it should be noticed that the company's cash ratio is returning to normal in 2021.
The current situation can be maintained and gets better with the optimized policies mentioned.

\subsection{Develop New Products}

The trends of RTAT, ROE and ROC have all witnessed growth until 2019, following a decline. On the one hand, Return on Equity is largely determined by a firm's profit margin on sales, asset turnover and leverage ratio., Return on Total Assets Ratio can be increased by increasing revenue, economizing the use of funds, and improvement of the operation as well as management of enterprises. These indicators highlight the importance of providing a high quality of service and products, also, operation of an enterprise. To be specific, Beyond Meat should make its products more competitive among peer enterprises. For example, Impossible Foods, which has long been Beyond Meat's main rival, concentrates more on appearance and taste and is often commented as a knockoff of the real thing. The previous novel products such as Beast Burger, made from pea protein isolates, and Chicken stripes created many profits. Their health ingredients and meatlike texture popularize the brand as well as their products. What's more, Beyond Meat launched seafood products recently and attracted customers either concerning the health risks or price factors. Thus, Beyond Meat can focus on developing new products to accommodate costumers' favors.

\subsection{Optimum Proposal}

What's more, the company keeps receiving a great number of venture funds since the year it was built up. However, Beyond Meat can't rely on the funds to maintain its profits at present. Thus, the fluctuation in product sales is critical to the company's profits. Rather, as a solution proposed above, Beyond Meat can develop new products to increase sales. In addition to the venture funds, the company will increase sales by cooperating with other catering companies or strengthening the partnership like McDonald's and Walmart.

\section{CONCLUSION}

To sum up the problems that lead to deficit in revenue for Beyond Meat, the data from financial indicators and graphs representing the data trend provide an explanation. First of all, the Operating Profit Ratio has witnessed a decrease since 2019, noting the problem associates with company's operating ability. The company should open up new markets and advertise the products to more variety of costumers. What's more, the Ratio of Profits to Cost and Expense indicates a similar decline in recent years. Given that the company's operating results can't cover the operating expenses, Beyond Meat should properly reduce its 
operating costs. Then, the graph of Earning/Cash Ratio (Figure 4) points out that the value once fell below 1, indicating a current negative net profit and a poor degree of cash flow. To reverse the situation, the firm can take part in a financial investment project or invest in other enterprises to collect cash income. As an analysis of the Return on Total Assets Ratio, Equity and Capital, which share a similar trend of decline after 2019, the poor efficiency of shareholders' funds, problems associated with enterprise's own equity and a drawback within overall profitability of all assets are highlighted. The solution is to increase the net margin of the products and review an overall increase in capital gains, which attracts investors for this enterprise. In order to popularize the products, Beyond Meat should focus on developing novel meat alternatives.

This study's finding involves limitation since the enterprise Beyond Meat has its market dominated in certain nations or regions. Therefore, its application in predicting the worldwide sales problems would be more or less inaccurate. What's more, due to the impact of pandemic, problems associated with the enterprise's operations and regulations would be overpredicted. Furthermore, it lacks access to obtaining primary data sources by conducting surveys or interviews.

\section{REFERENCES}

[1] Wikipedia, https://en.wikipedia.org/wiki/Cultured_meat.

[2] Wikipedia, https://en.wikipedia.org/wiki/Artificial_meat.

[3] H. L. Tuomisto, M. Mattos, Environmental impacts of cultured meat production in: Environmental Science \& Technology, vol. 45(14), 2011, pp. 6117-6123.

DOI: https://doi.org/10.1021/es200130u.

[4] Stephen J. Bronner, With $\$ 72$ million in funding, the entrepreneur behind beyond meat pursues innovation over profit, 2018. Entrepreneur, https://www.entrepreneur.com/article/307715.

[5] D. Choudhury, Ting, T. Wei, E. Swartz, The business of cultured meat in: Trends in Biotechnology, vol.38(6), 2020, pp. 573-577. DOI: https://doi.org/10.1021/es200130u.

[6] Jonathan Shieber, Competition among alternative protein players gets hot as companies beef up with new deals, 2019. TechCrunch, https://techcrunch.com/2019/08/11/competitionamong-alternative-protein-players-gets-hot-ascompanies-beef-up-with-new-deals.

[7] D. Choudhury, S. Singh, J. Si, S. Han, L.P. Tan, Commercialization of plant-based meat alternatives in: Trends in Plant Science, 2020. DOI: https://doi.org/10.1016/j.tplants.2020.08.006.

[8] Godfray et al., Meat consumption, health, and the environment in: Science, 2018. DOI: https://doi.org/10.1126/science.aam5324.

[9] Al Root, Beyond Meat stock is sinking because dreadful sales took everyone by surprise, 2020. Barron's, https://www.barrons.com/articles/beyond-meatstock-sinks-because-dreadful-sales-took-everyoneby-surprise-51604960149.

[10] Jack Caulfield, A step-by-step guide to literary analysis, $2020 . \quad$ Scribbr, https://www.scribbr.com/academic-essay/literaryanalysis.

[11] Gerring, John, Case Study Research: Principles and Practices, Cambridge University Press, 2007. DOI: https://doi.org/10.1017/CBO9780511803123.

[12] Wikipedia, https://en.wikipedia.org/wiki/Analytic_induction.

[13] Macabacus, https://macabacus.com/valuation/comparablecompanies.

[14]Christine Hall, The science behind alternative proteins has startups, investors digging in, 2021. CrunchbaseNews, https://news.crunchbase.com/news/the-sciencebehind-alternative-proteins-has-startups-investorsdigging-in.

[15] Yahoo Finance, https://finance.yahoo.com/quote/BYND/keystatistics? $\mathrm{p}=\mathrm{BYND}$. 